\title{
Sử dụng phương tiện truyền thông xã hội quá mức và hiệu suất công việc nhân viên ủy ban nhân dân quận Bình Thạnh, Thành phố Hồ Chí Minh
}

\section{Excessive use of social media and employee's job performance at the people's committee of Binh Thanh district Ho Chi Minh City}

\author{
Cao Minh Trí ${ }^{*}$, Nguyễn Huỳnh Anh Thữ ${ }^{2}$, Lê Thị Ngọc Tú ${ }^{1}$ \\ ${ }^{1}$ Trường Đại học Mở Thành phố Hồ Chí Minh, Việt Nam \\ ${ }^{2}$ Ủy ban nhân dân quận Bình Thạnh, Thành phố Hồ Chí Minh, Việt Nam \\ *Tác giả liên hệ, Email: tri.cm@ou.edu.vn
}

THÔNG TIN

DOI: $10.46223 / \mathrm{HCMCOUJS}$ econ.vi.17.1.919.2022

Ngày nhận: 25/08/2020

Ngày nhận lại: 26/02/2021

Duyệt đăng: 09/03/2021

Tù khóa:

căng thẳng trong công việc; hiệu suất công việc; sử dụng quá mức; truyền thông xã hội; xung đột công nghệ - công việc

\section{TÓM TẮT}

Truyền thông xã hội là một trong những công cụ xây dựng cộng đồng, cho phép người dùng kết nối với người khác bất kể vị trí và thời gian. Người lao động sử dụng các ứng dụng truyền thông xã hội khác nhau để chia sẻ kiến thức, giải quyết vấn đề, hợp tác và giao tiếp trong các tổ chức (Aral, Dellarocas, \& Godes, 2013; Landers \& Schmidt, 2016), từ đó nâng cao hiệu suất công việc. Tuy nhiên, việc truy cập vào phương tiện truyền thông xã hội có nhiều khả năng dẫn đến việc sử dụng quá mức và vô tình tạo ra một môi trường làm việc căng thẳng hơn, dẫn đến kết quả tiêu cực trong các tổ chức (Cao \& Yu, 2019).

Nghiên cứu này xác định sự tác động và mức độ tác động của các kiểu sử dụng quá mức khác nhau của mạng xã hội đối với hiệu suất công việc thông qua sự căng thẳng tại nơi làm việc của 328 người lao động tại Uy ban nhân dân quận Bình Thạnh (Thành phố Hồ Chí Minh, Việt Nam), cụ thể là các trưởng phó phòng ban và nhân viên làm việc trong văn phòng, được khảo sát trực tuyến vào tháng 05 năm 2020. Tính hợp lệ và độ tin cậy của dữ liệu đã được kiểm tra bằng $\mathrm{CFA}$ và $\mathrm{SEM}$.

Kết quả của nghiên cứu này cho thấy Sử dụng quá mức nhu cầu xã hội của phương tiện truyền thông xã hội tại nơi làm việc tác động mạnh nhất và đáng kể tới sự căng thẳng tại nơi làm việc. Kế đến là Sử dụng quá mức nhu cầu thụ hưởng và Xung đột công nghệ-công việc. Sự căng thẳng tại nơi làm việc có tác động ngược chiều với hiệu suất công việc. Tuy nhiên, Sử dụng quá mức nhu cầu nhận thức không có mối quan hệ với sự căng thẳng tại nơi làm việc. Một số hàm ý quản trị được đề xuất dựa vào kết quả nghiên cứu để có thể sử dụng hợp lý phương tiện truyền thông xã hội, từ đó cải thiện mối quan hệ và hiệu suất của người lao động.

\section{ABSTRACT}

Social media is one of the largest community-building tools ever, allowing users to connect with others regardless of location and time. Employees use various social media applications to 
share knowledge, solve problems, collaborate, and communicate within organizations (Aral, Dellarocas, \& Godes, 2013; Landers \& Schmidt, 2016), improving jobs's performance. However, access to social media is more likely to lead to overuse and inadvertently create a more stressful work environment, leading to negative results in organizations (Cao \& Yu, 2019).

This research aims to identify the effects and their level of social media's different excessive usage patterns on employee job performance with the intermediate role of Strain at work. The online survey was conducted on 328 employees at the People's Committee of Binh Thanh District (Ho Chi Minh City) in May 2020, including office managers and staff. The validity and reliability of the data have been tested using CFA and SEM.

The result shows that Excessive use of social needs has the most positive effect on Strain at work. Then are Excessive use of hedonic needs at work and Technology-work conflict. Strain at work has a negative impact on job performance. However,

Keywords: Excessive use of cognitive needs does not have a relationship with strain at work; job performance; Strain at work. Some managerial implications are proposed to excessive use; social media; technology-work conflict help appropriate social media use to better relationships and employee job performance.

\section{Sự cần thiết của nghiên cứu}

Phương tiện truyền thông xã hội đã mang lại nhiều thực tiễn mới trong quản lý cho các tổ chức, từ việc tạo ra các mô hình kinh doanh sáng tạo đến chuyển đổi giao tiếp, hợp tác và chia sẻ kiến thức. Trong môi trường làm việc, nhiều nghiên cứu cho thấy các ứng dụng truyền thông xã hội có thể nâng cao hiệu suất và năng suất làm việc của từng cá nhân (Aral et al., 2013; Alalwan, Rana, Dwivedi, \& Algharabat, 2017; Cao \& Ali, 2018; Dwivedi, Kapoor, \& Chen, 2015; Landers \& Schmidt, 2016; Moqbel, Nevo, \& Kock, 2013). Các nghiên cứu trước đây bắt nguồn từ giả thuyết cơ bản chỉ ra rằng nếu phương tiện truyền thông xã hội được sử dụng hợp lý trong công việc, thì kết quả sẽ rất khả quan. Tuy nhiên, theo Kaplan và Haenlein (2012), việc sử dụng công nghệ có thể có những hậu quả tiêu cực khi vượt quá mức sử dụng. Sự thâm nhập của điện thoại thông minh và phương tiện truyền thông xã hội di động đã cho phép người dùng kết nối với người khác bất kể vị trí và thời gian cũng như ranh giới mờ giữa công việc và cuộc sống. Khi các mối quan hệ xã hội tham gia hoạt động trên phương tiện truyền thông, mọi người có xu hướng sử dụng quá mức, có thể thay đổi cách làm việc truyền thống của họ không hợp lý, gây ra những ảnh hưởng tiêu cực nghiêm trọng đối với các cá nhân và tổ chức (Wang, Lee, \& Hua, 2015).

Ngày nay, không chỉ riêng những doanh nghiệp tư nhân mới tìm cách làm hài lòng khách hàng, mà ngay cả trong khu vực hành chính công cũng đặt sự hài lòng của người dân lên trên hết. Tuy nhiên, thời gian qua, theo những ý kiến phản hồi về sự hài lòng từ dịch vụ công trực tuyến tại Ủy ban nhân dân quận Bình Thạnh (Thành phố Hồ Chí Minh, Việt Nam) - cơ quan thực thi pháp luật với hệ thống một cửa tiếp dân - đã xảy ra nhiều trường hợp người dân phàn nàn về thủ tục hành chính như việc giải quyết, trả kết quả hồ sơ chậm trễ và thái độ phục vụ của một số nhân viên chưa tốt. Mặc dù chưa có những khảo sát, đánh giá chính thức nhưng có thể nhận thấy mức độ hài lòng của người dân về thủ tục hành chính hiện nay chưa cao, đặc biệt là tại Ủy ban nhân dân quận Bình Thạnh.

Một trong những lý do được giải thích cho vấn đề này là sự thiếu tập trung trong lúc làm việc của nhân viên. Với công nghệ kỹ thuật số, họ sử dụng các phương tiện truyền thông 
làm việc riêng như đọc báo, lướt web, tán gẫu ... từ đó dẫn đến không đạt được hiệu suất làm việc, phục vụ dân chậm. Quá nhiều giao tiếp qua phương tiện truyền thông xã hội có thể gây ra tình trạng quá tải và mất tập trung thông tin, gây nhầm lẫn sự tập trung của nhân viên và cản trở khả năng đưa ra quyết định (Madsen \& Slatten, 2015). Vì vậy việc nghiên cứu những tác động khi sử dụng phương tiện truyền thông xã hội quá mức đến hiệu suất công việc của người lao động tại Ủy ban nhân dân quận Bình Thạnh (Thành phố Hồ Chí Minh) là cần thiết nhằm đề xuất những chính sách cho các nhà quản lý nhân sự trong việc hạn chế sử dụng công cụ truyền thông xã hội hoặc đưa ra cách quản lý, tiêu chí sử dụng như thế nào để giảm căng thẳng và nâng cao hiệu suất làm việc của người lao động nơi làm việc.

\section{Cơ sở lý thuyết}

Phương tiện truyền thông xã hội là một nền tảng thông qua đó mọi người kết nối hoặc cộng tác với nhau trong và ngoài các tổ chức, không chỉ cung cấp một hệ thống quản lý kiến thức hoàn chỉnh mà còn là các công cụ rất đơn giản và linh hoạt cho quản lý (Cao \& Ali, 2018). Vì vậy định nghĩa về phương tiện truyền thông xã hội nói chung, được dựa trên hai khía cạnh quan trọng: Internet và tương tác công khai. Zahoor và Qureshi (2017) đã định nghĩa phương tiện truyền thông xã hội là công nghệ web được sử dụng để tương tác với cộng đồng công cộng. Phương tiện truyền thông xã hội là một nhóm các ứng dụng dựa trên Internet được xây dựng trên nền tảng tư tưởng và công nghệ của Web 2.0 (Tajvidi \& Karami, 2017). Phương tiện truyền thông xã hội cung cấp nhận dạng mạng xã hội cho người dùng để thiết lập hồ sơ cho các hoạt động xã hội và cũng cho phép người dùng tạo và trao đổi nội dung do người dùng tạo mà không bị giới hạn về thời gian và không gian (Carr \& Hayes, 2015; Kaplan \& Haenlein, 2012; Özdemir \& Erdem, 2016). Các mạng xã hội này cung cấp các tính năng tìm kiếm và quyền riêng tư cho người dùng của họ. Ngoài ra, người dùng cũng có thể đưa ra danh sách những người dùng khác mà họ chia sẻ và tương tác (Kane, Alavi, Labianca, \& Borgatti, 2012). Do đó, các tổ chức ngày càng quan tâm đến việc sử dụng phương tiện truyền thông xã hội để xây dựng mối quan hệ với nhân viên (Macnamara \& Zerfass, 2012). Các tổ chức cũng sử dụng phương tiện truyền thông xã hội để quảng bá sản phẩm nhằm tăng sức mạnh thu hút khách hàng quan tâm (Aichner \& Jacob, 2014).

Có nhiều ứng dụng mạng xã hội có sẵn mà các tổ chức sử dụng cho mục đích chính thức của họ như Facebook, WhatsApp, YouTube, Twitter, Blog, Skype và các trang chia sẻ hình ảnh. Ngoài ra, một số mạng xã hội đặc biệt và riêng tư cũng được sử dụng để liên lạc trong các tổ chức, ví dụ như Yam Yamher, trong khi một số ít tổ chức sử dụng podcast, cuộc sống thứ hai và Pinterest (Macnamara \& Zerfass, 2012).

Hiệu suất công việc đề cập đến chất lượng công việc của một người khi thực hiện công việc, gắn liền với khả năng người lao động nhận thức các mục tiêu được giao, hoàn thành kỳ vọng và đạt được mục tiêu theo yêu cầu của tổ chức (Sparrowe, Liden, Wayne, \& Kraimer, 2001). Hiệu suất công việc liên quan trực tiếp đến hiệu quả công việc của người lao động vì hiệu suất của nhân viên có xu hướng tăng hoặc giảm theo sự căng thẳng tại nơi làm việc (Haque \& Aston, 2016). Catalsakal (2016) đã xem xét các khía cạnh hiệu suất làm việc của nhân viên như hiệu suất theo ngữ cảnh, hiệu suất thích ứng, hiệu suất sáng tạo và hiệu suất nhanh nhẹn. Nghiên cứu này cũng như Ayyagari, Grover, và Purvis (2011); Ofir, Alexander, và Bontis (2011); Hassan, Nevo, và Wade (2015); Song, Wang, Benitez, Chen, và Hu (2019); Cao và Yu (2019) sử dụng khái niệm theo Katz (1964): hai thành phần của hiệu suất công việc gồm các hoạt động thường xuyên được thực hiện theo cách thức nhất quán, đáng tin cậy và các hoạt động đổi mới vượt ra ngoài các hoạt động thông thường để cung cấp kết quả mới và hữu ích.

Thành phần đầu tiên, được dán nhãn hiệu suất công việc thường xuyên, đại diện cho hiệu suất của các nhiệm vụ, trách nhiệm liên quan đến công việc bắt buộc, tất cả đều được đánh giá và khen thưởng bởi tổ chức sử dụng lao động (Janssen \& Yperen, 2004; Sparrowe et al., 2001). 
Hiệu suất công việc thường xuyên bao gồm những việc làm việc tất cả các giờ được giao, hoàn thành nhiệm vụ đúng hạn, tuân thủ các quy tắc và quy định (O'Reilly \& Chatman, 1986), thực hiện đầy đủ các trách nhiệm thiết yếu (Sparrowe et al., 2001) và hoàn thành tất cả nhiệm vụ công việc yêu cầu (Janssen \& Yperen, 2004).

Thành phần thứ hai của hiệu suất công việc cá nhân dựa trên hành vi tùy ý vượt ra ngoài mô tả công việc chính thức (Sparrowe et al., 2001) và được giải thích là hiệu suất công việc sáng tạo (Janssen \& Yperen, 2004; Scott \& Bruce, 1994). Hiệu suất công việc sáng tạo được định nghĩa là sản xuất hoặc áp dụng các ý tưởng sáng tạo và hữu ích, được thực hiện tại nơi làm việc (Amabile, Conti, Coon, Lazenby, \& Herron, 1996; Scott \& Bruce, 1994). Nó giải quyết các vấn đề, cơ hội và tình huống bất thường, tạo ra và áp dụng các ý tưởng, xây dựng liên minh và thâu gom sức mạnh cần thiết để thực hiện thành công những cải tiến mới (Kanter, 1988). Các nhiệm vụ này được thực hiện bởi các cá nhân đồng thời, hoặc theo trình tự và đại diện cho cốt lõi của đổi mới tổ chức.

Với sự phát triển nhanh chóng của công nghệ di động và thiết bị thông minh, các phương tiện truyền thông xã hội như wiki, blog, tin nhắn tức thời và các trang mạng xã hội có thể được sử dụng để xã hội hóa, giải trí, tự quảng bá, giao tiếp và tìm kiếm thông tin (Park, Kee, \& Valenzuela, 2009) bởi hầu hết mọi người, mọi nơi, mọi lúc. Bị thu hút bởi sự phổ biến và tiện lợi của phương tiện truyền thông xã hội, phương tiện truyền thông xã hội hiện đang trở thành một phần không thể thiếu trong đời sống tổ chức (Koch, Gonzalez, \& Leidner, 2012). Người lao động sử dụng các ứng dụng truyền thông xã hội khác nhau để chia sẻ kiến thức, giải quyết vấn đề, hợp tác và giao tiếp trong các tổ chức, từ đó nâng cao hiệu suất công việc (Aral et al., 2013; Landers \& Schmidt, 2016).

Tuy nhiên, việc truy cập vào phương tiện truyền thông xã hội có nhiều khả năng dẫn đến việc sử dụng quá mức và vô tình tạo ra một môi trường làm việc căng thẳng hơn $(\mathrm{CaO} \& \mathrm{Yu}$, 2019). Xung đột công việc - công nghệ phản ánh việc sử dụng quá nhiều công nghệ trong môi trường công sở, điều này có thể gây ra hiệu suất làm việc kém, và các nhiệm vụ bị lãng quên, thậm chí điều này có thể ảnh hưởng đến sức khỏe như sự khó chịu ở cổ, mắt và ngón tay (Davis, 2001; Niemz, Griffiths, \& Banyard, 2005).

Lý thuyết giao dịch của sự căng thẳng và đối phó được sử dụng rộng rãi làm cơ sở để hiểu về công nghệ trong môi trường làm việc (Lee et al., 2016; Srivastava, Pant, Abraham, \& Agrawal, 2015). Nó giải thích hiện tượng căng thẳng như một giao dịch giữa một người và môi trường xung quanh (Lazarus \& Folkman, 1987). Giao dịch này phụ thuộc vào tác động của những người tạo căng thẳng, đó là nhu cầu môi trường phá vỡ sự cân bằng và do đó ảnh hưởng đến phản ứng tâm lý và phản ứng hành vi của cá nhân, đòi hỏi hành động của cá nhân để khôi phục sự cân bằng. Lý thuyết này xem các tác nhân gây căng thẳng là thành phần cốt lõi. Các yếu tố gây căng thẳng là các kích thích mà các cá nhân gặp phải và căng thẳng là phản ứng tâm lý của các cá nhân đối với các yếu tố này.

Đã có nhiều nghiên cứu sâu rộng về công nghệ trong môi trường làm việc thông qua tình trạng quá tải như một yếu tố gây căng thẳng đại diện. Các học giả đã áp dụng khái niệm này cho các lĩnh vực nghiên cứu khác nhau để mô tả nhận thức về các loại điều vượt quá khả năng của cá nhân để đối phó (Zhang, Gao, Chen, Sun, \& Pablos, 2015), như quá tải do công nghệ (Wisniewski \& Lu, 2010), quá tải xã hội (Maier, Laumer, Eckhardt, \& Weitzel, 2015). Rõ ràng, căng thẳng là kết quả tâm lý của việc sử dụng quá mức một công nghệ với thời gian dài hơn dự kiến (Caplan \& High, 2006).

Trong nghiên cứu về mạng xã hội (SNSs - Social Networking Sites), các biến số căng thẳng tâm lý như mệt mỏi và kiệt sức được nghiên cứu rộng rãi nhất trong bối cảnh của tổ chức làm việc. Hơn nữa, tại nơi làm việc, căng thẳng có thể dẫn đến kết quả bất lợi của tổ chức. Ví dụ, 
Ahuja, Chudoba, Kacmar, Mcknight, và George (2007) đã xem xét rằng kiệt sức công việc có thể làm giảm cam kết của tổ chức và giảm doanh thu.

Sử dụng phương tiện truyền thông xã hội tại nơi làm việc có thể ảnh hưởng tiêu cực đến hiệu suất công việc. Việc sử dụng phương tiện truyền thông xã hội tại nơi làm việc có thể khiến nhân viên sử dụng sai tài nguyên tổ chức, thời gian chính thức và thường bị coi là nhân viên đi chệch khỏi nơi làm việc, vi phạm các quy trình hoạt động tiêu chuẩn của tổ chức; từ đó, làm suy yếu hiệu suất công việc của nhân viên. Tuy nhiên, từ trước đến nay, chỉ có vài nghiên cứu về vấn đề này (Bảng 1).

\section{Bảng 1}

Các nghiên cứu liên quan

\begin{tabular}{|c|c|c|c|}
\hline STT & Tên tác giả & Tên đề tài & Kết quả nghiên cứu \\
\hline 1 & $\begin{array}{l}\text { Ayyagari } \\
\text { và cộng sự } \\
\text { (2011) }\end{array}$ & $\begin{array}{l}\text { Căng thẳng công nghệ: các } \\
\text { tiền tố và hàm ý }\end{array}$ & $\begin{array}{l}\text { Quá tải công việc và sự mơ hồ về vai trò } \\
\text { được coi là hai yếu tố gây căng thẳng nhất } \\
\text { khi tham gia công việc thông qua công nghệ } \\
\text { thông tin và truyền thông, các đặc tính công } \\
\text { nghệ xâm nhập được coi là yếu tố dự báo } \\
\text { chi phối của yếu tố gây căng thẳng }\end{array}$ \\
\hline 2 & $\begin{array}{l}\text { Ofir và } \\
\text { cộng sự } \\
\text { (2011) }\end{array}$ & $\begin{array}{l}\text { Sự xung đột của gia đình và } \\
\text { công việc liên quan đến việc } \\
\text { nghiện công nghệ tại cơ quan }\end{array}$ & $\begin{array}{l}\text { Nghiện công nghệ của tổ chức có thể ảnh } \\
\text { hưởng đến vấn đề quá tải công việc và cuộc } \\
\text { sống gia đình. Mức độ quá tải của công việc } \\
\text { càng cao thì xung đột gia đình - công nghệ } \\
\text { sẽ càng tăng cao }\end{array}$ \\
\hline 3 & $\begin{array}{l}\text { Hassan và } \\
\text { cộng sự } \\
(2015)\end{array}$ & $\begin{array}{l}\text { Khía cạnh liên kết giữa sữ } \\
\text { dụng phương tiện truyền } \\
\text { thông xã hội với hiệu suất } \\
\text { công việc: Vai trò của vốn xã } \\
\text { hội }\end{array}$ & $\begin{array}{l}\text { Phương tiện xã hội có tác động tiêu cực đối } \\
\text { với hiệu suất công việc hàng ngày nhứng lại } \\
\text { có tác động tích cực đối với hiệu suất công } \\
\text { việc sáng tạo }\end{array}$ \\
\hline 4 & $\begin{array}{l}\text { Song và } \\
\text { cộng sự } \\
\text { (2019) }\end{array}$ & $\begin{array}{l}\text { Tác động của việc sử dụng } \\
\text { phương tiện truyền thông xã } \\
\text { hội tại nơi làm việc đến hiệu } \\
\text { suất của nhóm và nhân viên }\end{array}$ & $\begin{array}{l}\text { Phương tiện truyền thông xã hội theo định } \\
\text { hướng công việc (DingTalk) và phương tiện } \\
\text { xã hội định hướng xã hội hóa (WeChat) đều } \\
\text { có tác động tích cực đáng kể trong việc cải } \\
\text { thiện hiệu suất của nhóm và cá nhân }\end{array}$ \\
\hline 5 & $\begin{array}{l}\text { Cao và Yu } \\
\text { (2019) }\end{array}$ & $\begin{array}{l}\text { Khám phá ảnh hưởng của } \\
\text { việc sử dụng phương tiện } \\
\text { truyền thông xã hội quá mức } \\
\text { tại nơi làm việc: Quan điểm } \\
\text { sử dụng ba chiều }\end{array}$ & $\begin{array}{l}\text { Việc sử dụng thụ hưởng quá mức trong } \\
\text { công việc đã ảnh hưởng đáng kể đến xung } \\
\text { đột công việc - công nghệ, trong khi việc sử } \\
\text { dụng nhận thức quá mức chỉ liên quan tiêu } \\
\text { cực đến căng thẳng }\end{array}$ \\
\hline
\end{tabular}

Nguồn: Nhóm tác giả tổng hợp

Nghiên cứu này thừa kế và hiệu chỉnh thang đo từ các nghiên cứu nêu trên để khảo sát tác động của các yếu tố về việc sử dụng quá mức (từ 02 - 04 giờ) các nhu cầu, xung đột công nghệ - công việc đến hiệu suất làm việc của người lao động thông qua yếu tố trung gian là sự căng thẳng tại Ủy ban nhân dân quận Bình Thạnh, Thành phố Hồ Chí Minh. Trong đó, thang đo của Cao và Yu (2019) là rõ ràng và đầy đủ nhất, phù hợp với tính chất công việc và bối cảnh tại đơn vị nghiên cứu. 




Hình 1. Mô hình và các giả thuyết nghiên cứu đề xuất

Trong những năm gần đây, việc sử dụng phương tiện truyền thông xã hội tại nơi làm việc đang trở nên phổ biến hơn. Một số nghiên cứu đã tập trung vào các khía cạnh thông tin và giao tiếp của việc sử dụng phương tiện truyền thông xã hội tại nơi làm việc (Moskaliuk \& Kimmerle, 2009; Ou \& Davison, 2011; Zoonen, Verhoeven, \& Vliegenthart, 2017). Schmidt, Lelchook, và Martin (2016) báo cáo rằng phương tiện truyền thông xã hội có thể cung cấp lợi ích thông tin quan trọng; mọi người sử dụng phương tiện truyền thông xã hội để kết nối với đồng nghiệp có thể có được thông tin liên quan đến công việc. Sheer và Rice (2017) đã khám phá rằng nhân viên sử dụng công nghệ để liên lạc về công việc và kinh doanh. Những nghiên cứu này chỉ ra rằng phương tiện truyền thông xã hội chủ yếu được sử dụng cho các mục đích liên quan đến công việc trong các tổ chức. Tuy nhiên cùng với sự hấp dẫn và quá nhiều thông tin trên mạng xã hội khiến các nhân viên khó có thể kiềm chế với các hoạt động xã hội ngay cả khi họ đang ở trong môi trường làm việc (Koch et al., 2012). Ngoài việc tìm kiếm thông tin và liên lạc với những người khác cho các mục đích liên quan đến nhiệm vụ, nhân viên cũng có thể sử dụng phương tiện truyền thông xã hội để phát triển và duy trì mối quan hệ cá nhân với những người khác để xã hội hóa (Sun \& Shang, 2014). Các cá nhân sau đó bị lôi kéo vào các trạng thái căng thẳng vì họ đang phải hỗ trợ xã hội quá nhiều cho những người bạn ảo trên mạng xã hội của họ (Yang \& Lin, 2017).

Giả thuyết H1: Sủ dụng quá mức (tù 02 - 04 giờ) nhu cầu xã hội của phương tiện truyền thông xã hội có tác động cùng chiều với sự căng thẳng tại nơi làm việc

Có rất nhiều bằng chứng cho thấy rằng sử dụng công nghệ thông tin tại nơi làm việc cho mục đích hưởng thụ có khả năng ảnh hưởng tiêu cực đến hiệu suất công việc cá nhân (Hassan et al., 2015; Cao \& Yu, 2019). Lý do là thời gian sử dụng phương tiện truyền thông xã hội theo chủ nghĩa hưởng thụ sẽ khiến nhân viên mất ít thời gian hơn để thực hiện các nhiệm vụ công việc cụ thể của công ty và dẫn đến giảm hiệu quả của nhân viên. Nhiều tổ chức đã cấm sử dụng một số công cụ truyền thông xã hội như Facebook và YouTube vì sợ làm giảm hiệu quả của nhân viên. Quản lý thời gian thích hợp đã được chứng minh là có liên quan đến tăng hiệu suất công việc và lãng phí thời gian có thể dẫn đến lãng phí cơ hội (Barling, Cheung, \& Kelloway, 1996). Một tác động tiêu cực tiềm tàng khác của việc sử dụng phương tiện truyền thông xã hội để hưởng thụ là khả năng làm xao lãng nhân viên. Lý thuyết phân tâm - xung đột có thể được sử dụng để giải thích làm thế nào phân tâm có thể tạo ra xung đột chú ý (Baron, 1986). Trong một môi trường với các nhiệm vụ phức tạp, chẳng hạn như công việc tri thức, mức độ phân tâm cao có thể dẫn đến giảm hiệu suất công việc (Nicholson, Parboteeah, Nicholson, \& Valacich, 2005).

Giả thuyết H2: Sư dụng quá mức (tù 02-04 giò) nhu cầu thu hưởng của phưong tiện truyền thông xã hội có tác động cùng chiều với sụ căng thẳng tại nơi làm việc

Sử dụng phương tiện truyền thông vì nhu cầu nhận thức, tập trung vào việc tạo và chia sẻ nội dung, truy cập nội dung do người khác tạo ra, bao gồm chia sẻ ý kiến, câu chuyện, xếp hạng, hình ảnh và video (Hassan et al., 2015). Chức năng này chủ yếu được sử dụng bởi các nhân viên mong muốn đạt được và trao đổi thông tin để cải thiện hiệu suất công việc. Khi dành một lượng 
thời gian lớn để tạo và thu thập thông tin trong giờ làm việc, nhân viên tiếp xúc với quá nhiều thông tin sâu hơn và rộng hơn mức cần thiết (Landers \& Schmidt, 2016). Tình huống này có thể dẫn đến tình trạng quá tải thông tin khi một lượng lớn thông tin vượt quá khả năng mà một cá nhân có thể xử lý, họ có thể phải trải qua một cảm giác mất kiểm soát và ảnh hưởng đến các nhiệm vụ công việc bình thường của họ. Thông tin vô ích và dư thừa có thể ảnh hưởng đến khả năng của từng cá nhân để giải quyết vấn đề và đưa ra quyết định, do đó làm giảm hiệu quả công việc và thậm chí là ảnh hưởng tiêu cực đến trạng thái tâm lý của họ và do đó gây ra sự mệt mỏi về công nghệ.

Giả thuyết H3: Sủ dụng quá mức (tù 02 - 04 giờ) nhu cầu nhận thức của phuơng tiện truyền thông xã hội có tác động cùng chiều với sụ căng thẳng tại nơi làm việc

Căng thẳng kỹ thuật là sự căng thẳng của các cá nhân do việc sử dụng công nghệ của họ đã được kiểm tra rộng rãi trong bối cảnh tổ chức (Ayyagari et al., 2011). Khi các cá nhân nhận thấy khoảng cách giữa khả năng của họ và yêu cầu từ phương tiện truyền thông xã hội trong môi trường làm việc không phù hợp, ví dụ như họ không thể học cách sử dụng một phần mềm giao dịch liên quan đến công việc trong một thời gian ngắn sẽ có thể dẫn đến kết quả không mong muốn chẳng hạn như xung đột với công việc của họ dẫn đến căng thẳng. Khi nhân viên bị giới hạn về thời gian và năng lượng, việc sử dụng phương tiện truyền thông xã hội ngày càng không hợp lý cho các mục đích khác nhau có thể gây ra xung đột với nhiệm vụ công việc của họ.

Giả thuyết H4: Xung đột công nghệ - công việc có tác động cùng chiều với sụ căng thẳng tại nơi làm viẹc

Tiếp xúc với quá nhiều liên quan đến phương tiện truyền thông xã hội có thể dẫn đến căng thẳng tâm lý. Maier và cộng sự (2015) đã kiểm tra sự căng thẳng của tình trạng quá tải do công nghệ. Họ đã tìm thấy được phản ứng tâm lý khó chịu và vô thức của một cá nhân đối với các điều kiện căng thẳng trong môi trường truyền thông xã hội. Nó mô tả cảm giác mệt mỏi của một cá nhân từ việc sử dụng phương tiện truyền thông xã hội từ đó ảnh hưởng đến hiệu suất công việc tại công ty. làm việc

Giả thuyết H5: Sụ căng thẳng tại nơi làm việc có tác động ngược chiều với hiệu suất

\section{Thiết kế nghiên cứu}

Nghiên cứu được thực hiện qua ba giai đoạn: nghiên cứu định tính lần một để hình thành thang đo chính thức, nghiên cứu định lượng để khảo sát và nghiên cứu định tính lần hai với các chuyên gia để thảo luận kết quả.

Nghiên cứu định tính lần một được thực hiện bằng kỹ thuật thảo luận nhóm với 10 người lao động tại Ủy ban nhân dân quận Bình Thạnh - đây là những người biết sử dụng truyền thông xã hội nhằm khám phá yếu tố mới cho mô hình và thang đo nghiên cứu. Một nhóm phỏng vấn thường bao gồm một số người có chung một số đặc điểm nhất định phù hợp với chủ đề cuộc thảo luận. Nhóm 10 người này đại diện đầy đủ các phòng ban của đơn vị đã đưa ra ý kiến cá nhân và thảo luận chung về thang đo nghiên cứu.

Sau đó, tiếp tục thực hiện phỏng vấn sâu cùng với hai chuyên gia là quản lý nhân sự đang làm việc tại Ủy ban nhân dân quận Bình Thạnh nhằm đánh giá, hiệu chỉnh và bổ sung lại thang đo nghiên cứu cho phù hợp. Mặc dù hai chuyên gia thấy rằng các phương tiện truyền thông xã hội chứa một khối lượng lớn thông tin trong xã hội hiện nay và có ích trong việc thu thập thông tin, phục vụ công việc. Nhưng điều quan trọng là làm cách nào để cho nhân viên lên mạng tìm đúng và đủ thông tin mình cần rồi dừng để không phải sử dụng Internet trong thời gian dài hơn so với mục đích của mình.

Tất cả 12 người được phỏng vấn đều hiểu rõ và đồng ý với thang đo sau khi điều chỉnh một số từ ngữ cho phù hợp và dễ hiểu hơn với thang đo Likert 5 điểm (Bảng 2). 


\section{Bảng 2}

Thang đo nghiên cứu

\begin{tabular}{|c|c|c|c|c|c|}
\hline Nhân tố & Mã hóa & Thang đo gốc & Thang đo tác giả dịch và chỉnh sửa & Ghi chú & Nguồn \\
\hline & \multicolumn{3}{|c|}{$\begin{array}{l}\text { Trong công ty, tôi dành một lượng thời gian lớn (từ } 02 \text { - } 04 \text { giờ) sử dụng phương tiện } \\
\text { truyền thông xã hội để } \\
\text { In my organization, I spend an unusually large amount of time using social media to... }\end{array}$} & & \\
\hline \multirow{4}{*}{$\begin{array}{l}\text { Sử dụng xã } \\
\text { hội quá mức } \\
\text { nơi làm việc } \\
\text { Excessive } \\
\text { social use at } \\
\text { work }\end{array}$} & ESU1 & $\begin{array}{l}\text {...create new relationships at } \\
\text { work. }\end{array}$ & 1. Tạo mối quan hệ mới trong công việc. & \multirow{4}{*}{ Giữ nguyên } & \multirow{4}{*}{$\begin{array}{l}\text { Cao và Yu } \\
(2019)\end{array}$} \\
\hline & ESU2 & $\begin{array}{l}\text {...get to know people I would } \\
\text { otherwise not meet at work. }\end{array}$ & $\begin{array}{l}\text { 2. Làm quen với những người mà tôi sẽ } \\
\text { không gặp ở nơi làm việc }\end{array}$ & & \\
\hline & ESU3 & $\begin{array}{l}\text {...maintain close social } \\
\text { relationships with people at work. }\end{array}$ & $\begin{array}{l}\text { 3. Duy trì mối quan hệ xã hội chặt chẽ với } \\
\text { mọi người trong công việc }\end{array}$ & & \\
\hline & ESU4 & $\begin{array}{l}\text {...get acquainted withcolleagues } \\
\text { who share my interests. }\end{array}$ & $\begin{array}{l}\text { 4. Làm quen với các đồng nghiệp người mà } \\
\text { có thể mang lại lợi ích cho tôi. }\end{array}$ & & \\
\hline \multirow{5}{*}{$\begin{array}{l}\text { Sử dụng } \\
\text { hưởng thụ } \\
\text { quá mức nơi } \\
\text { làm việc - } \\
\text { Excessive } \\
\text { hedonic use } \\
\text { at work }\end{array}$} & \multicolumn{3}{|c|}{$\begin{array}{l}\text { Trong công ty, tôi dành một lượng thời gian lớn (từ } 02 \text { - } 04 \text { giờ) sử dụng phương tiện } \\
\text { truyền thông xã hội để } \\
\text { In my organization, I spend an unusually large amount of time using social media to... }\end{array}$} & & \\
\hline & EHU1 & ...enjoy my break. & 1. Tận hưởng thời gian nghỉ ngơi của tôi & Giữ nguyên & \multirow{3}{*}{$\begin{array}{l}\text { Cao và Yu } \\
(2019) ; \\
\text { Hassan và } \\
\text { cộng sự } \\
(2015)\end{array}$} \\
\hline & EHU2 & $\begin{array}{l}\text {...take a break and relax from } \\
\text { work. }\end{array}$ & 2. Nghỉ ngơi và thư giãn từ công việc & $\begin{array}{l}\text { Đáp viên đề nghị chỉnh sửa } \\
\text { thành "Giải tỏa căng thẳng } \\
\text { trong công viẹcc" cho rõ } \\
\text { nghĩa hơn }\end{array}$ & \\
\hline & EHU3 & ...entertain myself. & 3. Giải trí & Giữ nguyên & \\
\hline & EHU4 & & 4. Tận hưởng thú vui cá nhân & Đáp viên đề nghị bổ sung & $\begin{array}{l}\text { Nghiên cứu } \\
\text { định tính }\end{array}$ \\
\hline
\end{tabular}




\begin{tabular}{|c|c|c|c|c|c|}
\hline Nhân tố & Mã hóa & Thang đo gốc & Thang đo tác giả dịch và chỉnh sửa & Ghi chú & Nguồn \\
\hline \multirow{5}{*}{$\begin{array}{l}\text { Sử dụng nhận } \\
\text { thức quá mức } \\
\text { nơi làm việc - } \\
\text { Excessive } \\
\text { cognitive use } \\
\text { at work }\end{array}$} & \multicolumn{3}{|c|}{$\begin{array}{l}\text { Trong công ty, tôi dành một lượng thời gian lớn (từ } 02 \text { - } 04 \text { giờ) sử dụng phương tiện } \\
\text { truyền thông xã hội để } \\
\text { In my organization, I spend an unusually large amount of time using social media to... }\end{array}$} & & \\
\hline & ECU1 & ...share content with colleagues & 1. Chia sẻ nội dung với đồng nghiệp & Giữ nguyên & \multirow{4}{*}{$\begin{array}{l}\text { Cao và Yu } \\
(2019)\end{array}$} \\
\hline & ECU2 & $\begin{array}{l}\text {...create content in collaboration } \\
\text { with colleagues }\end{array}$ & $\begin{array}{l}\text { 2. Tạo nội dung hợp tác với các đồng } \\
\text { nghiệp }\end{array}$ & $\begin{array}{l}\text { Đáp viên đề nghị chỉnh sửa } \\
\text { thành “Tạo nội dung liên } \\
\text { quan đến công viẹc của } \\
\text { nhóm, đồng đội” cho rõ } \\
\text { nghĩa hơn }\end{array}$ & \\
\hline & ECU3 & ...create content for work & 3. Tạo nội dung cho công việc & \multirow[b]{2}{*}{ Giữ nguyên } & \\
\hline & ECU4 & $\begin{array}{l}\text {...access content created by my } \\
\text { colleagues }\end{array}$ & $\begin{array}{l}\text { 4. Truy cập nội dung được tạo bởi các đồng } \\
\text { nghiệp của tôi }\end{array}$ & & \\
\hline \multirow{3}{*}{$\begin{array}{l}\text { Xung đột } \\
\text { công viẹ̣c } \\
\text { công nghệ - } \\
\text { Technology- } \\
\text { work conflict }\end{array}$} & TWC1 & $\begin{array}{l}\text { The use of social media keeps me } \\
\text { from my work more than I would } \\
\text { like }\end{array}$ & $\begin{array}{l}\text { 1. Việc sử dụng phương tiện truyền thông } \\
\text { xã hội ảnh hướng đến công việc tại công ty } \\
\text { của tôi }\end{array}$ & \multirow{3}{*}{ Giữ nguyên } & \multirow{3}{*}{$\begin{array}{l}\text { Cao và Yu } \\
(2019)\end{array}$} \\
\hline & TWC2 & $\begin{array}{l}\text { The use of social media takes up } \\
\text { time that I feel I should spend on } \\
\text { my work }\end{array}$ & $\begin{array}{l}\text { 2. Tôi bỏ bê công việc ở công ty để dành } \\
\text { nhiều thời gian hơn cho việc sử dụng } \\
\text { phương tiện truyền thông xã hội }\end{array}$ & & \\
\hline & TWC3 & $\begin{array}{l}\text { I generally seem to have enough } \\
\text { time to use my social media and to } \\
\text { spend time on my work }\end{array}$ & $\begin{array}{l}\text { 3. Tôi thường có đủ thời gian để sử dụng } \\
\text { phương tiện truyền thông xã hội và dành } \\
\text { thời gian cho công việc của tôi }\end{array}$ & & \\
\hline \multirow{2}{*}{$\begin{array}{l}\text { Sự căng } \\
\text { thẳng - Strain }\end{array}$} & STR1 & $\begin{array}{l}\text { I feel drained from activities that } \\
\text { require me to use social media }\end{array}$ & $\begin{array}{l}\text { 1. Tôi cảm thấy kiệt sức từ các hoạt động } \\
\text { đòi hỏi tôi phải sử dụng phương tiện truyền } \\
\text { thông xã hội }\end{array}$ & \multirow[t]{2}{*}{ Giữ nguyên } & \multirow{2}{*}{$\begin{array}{l}\text { Cao và Yu } \\
(2019)\end{array}$} \\
\hline & STR2 & $\begin{array}{l}\text { I feel tired from my social media } \\
\text { activities }\end{array}$ & $\begin{array}{l}\text { 2. Tôi cảm thấy mệt mỏi với các hoạt động } \\
\text { truyền thông xã hội }\end{array}$ & & \\
\hline
\end{tabular}




\begin{tabular}{|c|c|c|c|c|c|}
\hline Nhân tố & Mã hóa & Thang đo gốc & Thang đo tác giả dịch và chỉnh sửa & Ghi chú & Nguồn \\
\hline & STR3 & $\begin{array}{l}\text { Working all day with social media } \\
\text { is a strain for me }\end{array}$ & $\begin{array}{l}\text { 3. Làm việc cả ngày với phương tiện truyền } \\
\text { thông xã hội là một sự căng thẳng đối với } \\
\text { tôi }\end{array}$ & & \\
\hline & STR4 & $\begin{array}{l}\text { I feel burned out from my social } \\
\text { media activities }\end{array}$ & $\begin{array}{l}\text { 4. Tôi cảm thấy kiệt sức từ các hoạt động } \\
\text { truyền thông xã hội của mình }\end{array}$ & & \\
\hline \multirow{4}{*}{$\begin{array}{l}\text { Hiệu suất } \\
\text { công việc } \\
\text { - Job } \\
\text { performance }\end{array}$} & JP1 & $\begin{array}{l}\text { I always complete the duties } \\
\text { specified in my job description }\end{array}$ & $\begin{array}{l}\text { 1. Tôi luôn hoàn thành các nhiệm vụ được } \\
\text { chỉ định trong mô tả công việc của tôi }\end{array}$ & \multirow{4}{*}{ Giữ nguyên } & \multirow{4}{*}{$\begin{array}{l}\text { Cao và Yu } \\
(2019)\end{array}$} \\
\hline & JP2 & $\begin{array}{l}\text { I always meet all the formal } \\
\text { performance requirements of my } \\
\text { job }\end{array}$ & $\begin{array}{l}\text { 2. Tôi luôn đáp ứng tất cả các yêu cầu thực } \\
\text { hiện chính thức trong công việc của tôi }\end{array}$ & & \\
\hline & JP3 & $\begin{array}{l}\text { I always fulfill all responsibilities } \\
\text { required by my job }\end{array}$ & $\begin{array}{l}\text { 3. Tôi luôn hoàn thành mọi trách nhiệm } \\
\text { theo yêu cầu của công việc }\end{array}$ & & \\
\hline & JP4 & $\begin{array}{l}\text { I usually perform well the } \\
\text { necessary tasks }\end{array}$ & $\begin{array}{l}\text { 4. Tôi thường thực hiện tốt các nhiệm vụ } \\
\text { cần thiết }\end{array}$ & & \\
\hline
\end{tabular}

Nguồn: Kết quả nghiên cứu định tính 
Tổng số cán bộ công nhân viên tại Ủy ban nhân dân quận Bình Thạnh có khoảng 600 người. Tuy nhiên, đối với đề tài sử dụng phương pháp phân tích nhân tố khám phá (EFA), Nguyen (2013) cho rằng tỉ lệ quan sát/biến đo lường là 5:1. Mô hình nghiên cứu có 23 biến đo lường. Nếu tính theo qui tắc năm mẫu/biến đo lường thì cỡ mẫu tối thiểu là 115 , vì vậy nghiên cứu chỉ khảo sát 400 người lao động tại Ủy ban nhân dân quận Bình Thạnh, cụ thể từ cấp trưởng, phó phòng ban, những nhân viên làm việc trong văn phòng. Vì tính chất công việc bận rộn và quy định của cơ quan trong thời điểm phòng chống đại dịch Covid-19, nên nhóm tác giả xây dựng bảng khảo sát trực tuyến trên Internet để gửi đến các đáp viên thông qua email để khi đáp viên có thời gian sau giờ làm việc sẽ thực hiện khảo sát.

Sau khi thu hồi các phiếu khảo sát và tiến hành loại bỏ 72 phiếu khảo sát không đạt yêu cầu, nghiên cứu tiến hành phân tích định lượng bằng phần mềm SPSS và Amos với kích thước mẫu nghiên cứu là 328 .

Khi có được kết quả từ nghiên cứu định lượng, nghiên cứu định tính lần hai sẽ thực hiện với sự tham gia của hai chuyên gia đã thực hiện nghiên cứu định tính lần một để thảo luận về kết quả nghiên cứu.

\section{Kết quả nghiên cứu và thảo luận}

\subsection{Kết quả nghiên cứu}

Kết quả phân tích cronbach's alpha cho thấy rằng, các tương quan biến tổng đều lớn hơn 0.3 nên không loại quan sát nào ra khỏi các thang đo, hệ số Cronbach's alpha của các thang đo lường đều đảm bảo lớn hơn 0.7 . Do vậy, thang đo lường các khái niệm trong nghiên cứu đảm bảo được độ tin cậy tốt để thực hiện các phân tích tiếp theo.

\section{Bảng 3}

Kết quả kiểm định Cronbach's Alpha và phân tích nhân tố

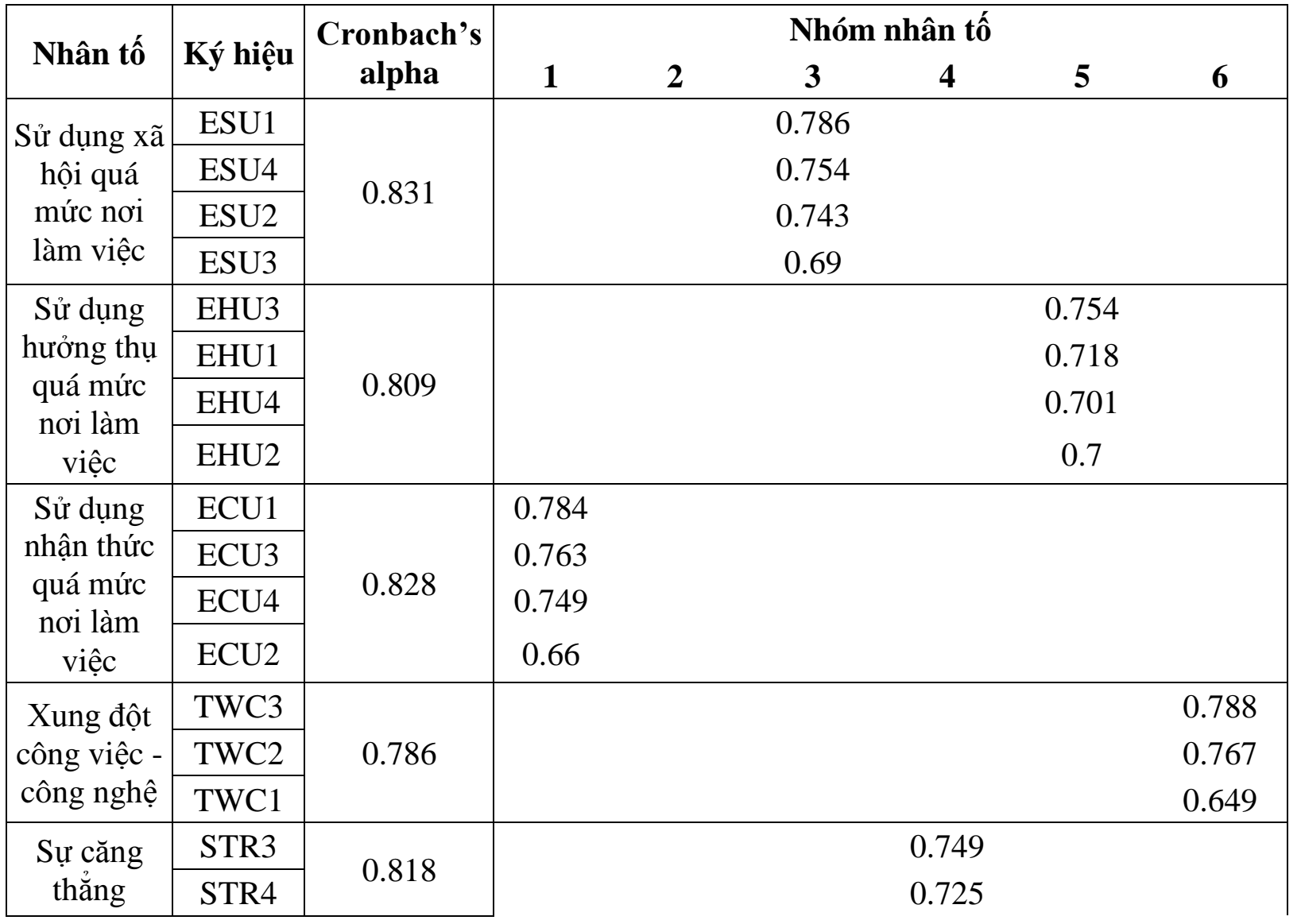






KMO của kiểm định Bartlett $=0.845$, với mức ý nghĩa 0.00 ;

Giá trị Eigenvalue $=1.615$; tổng phương sai trích là $55.15 \%$

Nguồn: Kết quả nghiên cứu định lượng

Phân tích EFA cho thấy không có quan sát nào bị loại ra khỏi thang đo lường các khái niệm nghiên cứu, các quan sát đều nhóm lại theo từng nhân tố rõ ràng như kỳ vọng, hệ số tải nhân tố tốt $(\geq 0.5)$. Hệ số KMO của kiểm định Bartlett là $0.845 \geq 0.5$, với mức ý nghĩa 0.00 ; giá trị Eigenvalue là $1.615 \geq 1$; tổng phương sai trích TVE là $55.15 \% \geq 50 \%$. Như vậy, quá trình phân tích EFA cho kết quả tất cả 23 biến quan sát đo lường cho 06 khái niệm nghiên cứu trong mô hình lý thuyết phù hợp tốt để tiến hành các phân tích tiếp theo (Hoang \& Chu, 2008).

Thông qua kết quả của việc phân tích CFA, hệ số Chi-square/df $=1.16 \leq 5$, với mức ý nghĩa $0.054>5 \%$ nhưng vẫn nhỏ hơn $10 \%$; RMSEA $=0.022 \leq 0.08$; GFI $=0.938 \geq 0.9$; CFI $=$ $0.987 \geq 0.9 ; \mathrm{TLI}=0.985 \geq 0.9$. Với kết quả này, thang đo đảm bảo tính phân biệt, tính hội tụ, tính đơn hướng, phù hợp tốt với dữ liệu nghiên cứu. Ngoài ra, độ tin cậy tổng hợp phải $\geq 0.7$ và phương sai trích $\geq 0.5$ của từng thang đo được tính toán đều đạt yêu cầu (chi tiết Bảng 4) (Jöreskog, 1971; Fornell \& Larcker, 1981).

\section{Bảng 4}

Kết quả tính toán độ tin cậy tổng hợp và phương sai trích

\begin{tabular}{|c|c|c|c|c|c|}
\hline \multicolumn{3}{|c|}{ Tương quan } & Estimate & Độ tin cậy tổng họpp & Phương sai trích \\
\hline ECU4 & $\leftarrow$ & ECU & 0.710 & \multirow{4}{*}{0.828} & \multirow{4}{*}{0.546} \\
\hline ECU3 & $\leftarrow$ & ECU & 0.775 & & \\
\hline ECU1 & $\leftarrow$ & ECU & 0.747 & & \\
\hline ECU2 & $\leftarrow$ & $\mathrm{ECU}$ & 0.723 & & \\
\hline ESU4 & $\leftarrow$ & ESU & 0.785 & \multirow{4}{*}{0.830} & \multirow{4}{*}{0.551} \\
\hline ESU1 & $\leftarrow$ & ESU & 0.745 & & \\
\hline ESU2 & $\leftarrow$ & ESU & 0.736 & & \\
\hline ESU3 & $\leftarrow$ & ESU & 0.700 & & \\
\hline JP1 & $\leftarrow$ & JP & 0.805 & \multirow{4}{*}{0.830} & \multirow{4}{*}{0.552} \\
\hline JP2 & $\leftarrow$ & $\mathrm{JP}$ & 0.777 & & \\
\hline JP3 & $\leftarrow$ & $\mathrm{JP}$ & 0.696 & & \\
\hline JP4 & $\leftarrow$ & JP & 0.686 & & \\
\hline STR3 & $\leftarrow$ & STR & 0.718 & \multirow{3}{*}{0.818} & \multirow{3}{*}{0.529} \\
\hline STR1 & $\leftarrow$ & STR & 0.744 & & \\
\hline STR2 & $\leftarrow$ & STR & 0.708 & & \\
\hline
\end{tabular}




\begin{tabular}{|c|c|c|c|c|c|}
\hline \multicolumn{3}{|c|}{ Tương quan } & Estimate & Độ tin cậy tổng hợp & Phương sai trích \\
\hline STR4 & $\leftarrow$ & STR & 0.739 & & \\
\hline EHU4 & $\leftarrow$ & EHU & 0.710 & \multirow{4}{*}{0.810} & \multirow{4}{*}{0.516} \\
\hline EHU3 & $\leftarrow$ & EHU & 0.758 & & \\
\hline EHU1 & $\leftarrow$ & EHU & 0.707 & & \\
\hline EHU2 & $\leftarrow$ & EHU & 0.697 & & \\
\hline TWC2 & $\leftarrow$ & TWC & 0.741 & \multirow{3}{*}{0.787} & \multirow{3}{*}{0.552} \\
\hline TWC1 & $\leftarrow$ & TWC & 0.723 & & \\
\hline TWC3 & $\leftarrow$ & TWC & 0.765 & & \\
\hline
\end{tabular}

Nguồn: Kết quả nghiên cứu định lượng

Kết quả phân tích mô hình cấu trúc tuyến tính (SEM) cho thấy các chỉ số Chi-square/df = $1.830 \leq 5 ; \mathrm{P}$-value $=0.00 \leq 0.05 ;$ RMSEA $=0.05 \leq 0.08 ;$ GFI $=0.892 \geq 0.8 ; \mathrm{CFI}=0.932 \geq 0.9$; $\mathrm{TLI}=0.923 \geq 0.9$. Kết quả như vậy cho phép nghiên cứu khẳng định được rằng, mô hình lý thuyết phù hợp tốt với dữ liệu nghiên cứu. Kết quả chi tiết về các mối quan hệ trong mô hình như trong Bảng 5 và Hình 2.

\section{Bảng 5}

Kết quả phân tích SEM

\begin{tabular}{lllccccc}
\hline \multicolumn{2}{c}{ Mối tương quan } & $\begin{array}{c}\text { Ước lượng chưa } \\
\text { chuẩn hóa }\end{array}$ & $\begin{array}{c}\text { Ước lượng đã } \\
\text { chuẩn hóa }\end{array}$ & S.E. & C.R. & P-value \\
\hline STR & $\leftarrow$ & ECU & 0.078 & 0.083 & 0.061 & 1.278 & 0.201 \\
$\mathrm{STR}$ & $\leftarrow$ & ESU & 0.179 & 0.215 & 0.056 & 3.217 & 0.001 \\
\hline $\mathrm{STR}$ & $\leftarrow$ & EHU & 0.196 & 0.190 & 0.069 & 2.822 & 0.005 \\
\hline $\mathrm{STR}$ & $\leftarrow$ & TWC & 0.141 & 0.164 & 0.058 & 2.426 & 0.015 \\
\hline $\mathrm{JP}$ & $\leftarrow$ & STR & -0.379 & -0.306 & 0.085 & -4.462 & $* * *$ \\
\hline
\end{tabular}

Ghi chú: S.E. là sai lệch chuẩn; C.R. là giá trị tới hạn; $\mathrm{P}$-value là mức ý nghĩa $(* * *$ thể hiện mức ý nghĩa $<1 \%)$ Nguồn: Kết quả nghiên cứu định lượng

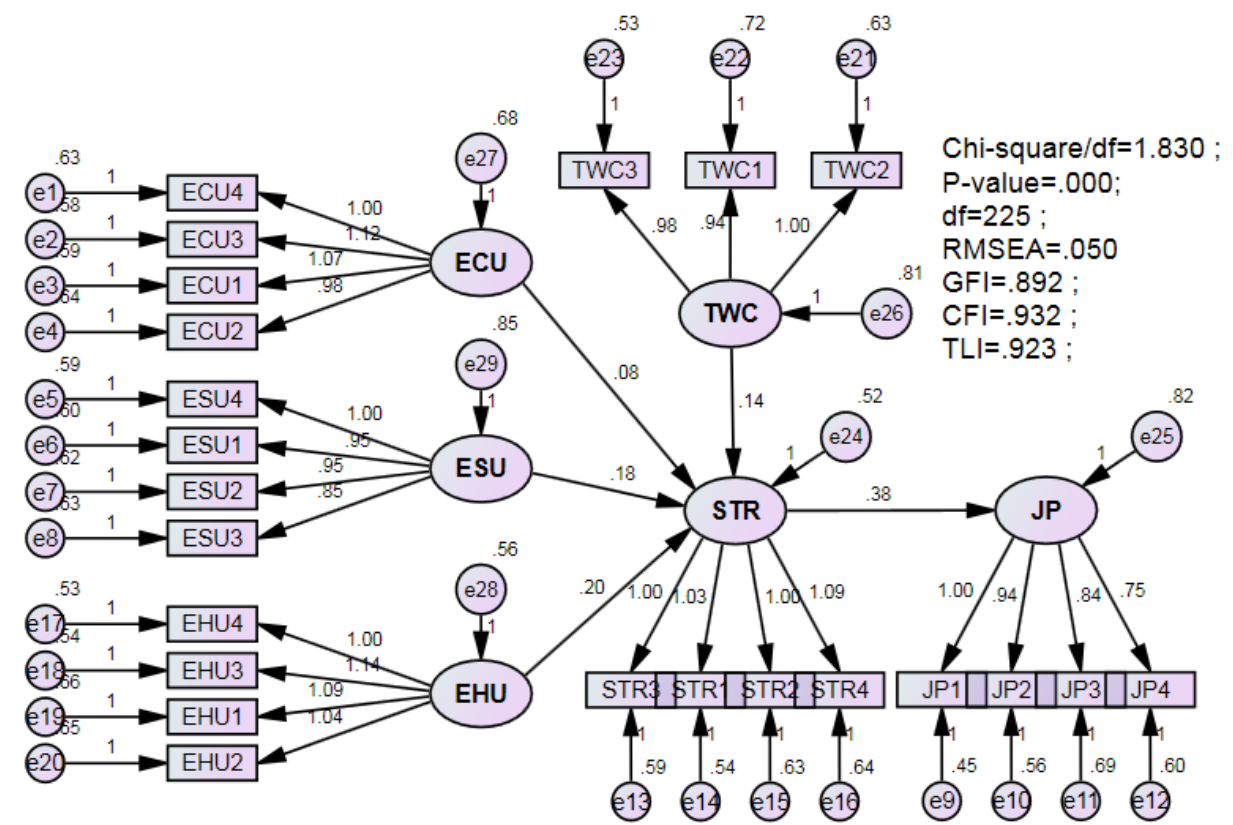

Hình 2. Kết quả phân tích SEM 
Kết quả kiểm định mô hình cấu trúc tuyến tính cho thấy hầu hết các mối tương quan trong mô hình đều có trọng số quan hệ tuyến tính cao và có độ tin cậy trên $95 \%$. Duy nhất mối quan hệ giữa ECU và STR là có hệ số tương quan tuyến tính rất thấp, không đạt độ tin cậy $95 \%$. Như vậy, các giả thuyết nghiên cứu được kết luận và tổng hợp lại trong Bảng 6 cho thấy, chỉ có giả thuyết $\mathrm{H} 3$ không được ủng hộ, các giả thuyết còn lại đều được ủng hộ.

\section{Bảng 6}

Kết quả kiểm định các giả thuyết nghiên cứu

\begin{tabular}{lccc}
\hline \multicolumn{1}{c}{ Giả thuyết nghiên cứu } & $\begin{array}{c}\text { Ước lượng } \\
\text { chuẩn hóa }\end{array}$ & $\begin{array}{c}\text { Mức ý nghĩa } \\
\text { đạt được }\end{array}$ & Kết luận \\
\hline $\begin{array}{l}\text { H1: Sử dụng quá mức (từ } 02-04 \text { giờ) nhu } \\
\text { cầu xã hội của phương tiện truyền thông xã } \\
\text { hội có tác động cùng chiều với sự căng } \\
\text { thẳng tại nơi làm việc. }\end{array}$ & 0.215 & 0.001 & $\begin{array}{l}\text { Giả thuyết được } \\
\text { ủng hộ }\end{array}$ \\
\hline $\begin{array}{l}\text { H2: Sử dụng quá mức (từ } 02-04 \text { giờ) nhu } \\
\text { cầu thụ hưởng của phương tiện truyền } \\
\text { thông xã hội có tác động cùng chiều với sự } \\
\text { căng thẳng tại nơi làm việc. }\end{array}$ & 0.190 & 0.005 & $\begin{array}{l}\text { Giả thuyết được } \\
\text { ủng hộ }\end{array}$ \\
\hline $\begin{array}{l}\text { H3: Sử dụng quá mức (từ 02 - 04 giờ) nhu } \\
\text { cầu nhận thức của phương tiện truyền } \\
\text { thông xã hội có tác động cùng chiều với sự } \\
\text { căng thẳng tại nơi làm việc. }\end{array}$ & 0.083 & 0.201 & $\begin{array}{l}\text { Giả thuyết } \\
\text { không được ủng } \\
\text { hộ }\end{array}$ \\
\hline $\begin{array}{l}\text { H4: Xung đột công nghệ - công việc tại } \\
\text { nơi làm việc có tác động cùng chiều với sự } \\
\text { căng thẳng tại nơi làm việc. }\end{array}$ & 0.164 & 0.015 & $\begin{array}{l}\text { Giả thuyết được } \\
\text { ủng hộ }\end{array}$ \\
\hline $\begin{array}{l}\text { H5: Sự căng thẳng tại nơi làm việc có tác } \\
\text { động ngược chiều với hiệu suất công việc. }\end{array}$ & -0.306 & $* * *$ & $\begin{array}{l}\text { Giả thuyết được } \\
\text { ủng hộ }\end{array}$ \\
\hline
\end{tabular}

Ghi chú: *** đạt mức ý nghĩa $<1 \%$

Nguồn: Kết quả nghiên cứu định lượng

\subsection{Thảo luận kết quả nghiên cứu}

\subsection{1. Ủng hộ giả thuyết $H 1$}

Kết quả này trái ngược với nghiên cứu của Cao và $\mathrm{Yu}$ (2019), khi họ cho rằng, việc sử dụng quá mức nhu cầu xã hội lại không ảnh hưởng đến sự căng thẳng trong công việc của nhân viên. Điểm khác biệt này có thể được giải thích bởi nhiều nguyên nhân, trong đó yếu tố văn hóa xã hội và yếu tố con người là rất quan trọng. Theo hai chuyên gia trong buổi thảo luận nghiên cứu định tính lần hai, nhiều nhân viên cơ quan hành chính như Ủy ban nhân dân thường dành thời gian cho phương tiện xã hội với mục đích làm quen với những người mà họ chưa từng gặp ở nơi làm việc, làm quen với các đồng nghiệp người mà có thể mang lại lợi ích cho họ, để duy trì mối quan hệ xã hội chặt chẽ với mọi người trong công việc, hay để tạo mối quan hệ mới trong công việc; từ đó, sẽ làm tăng thêm sự căng thẳng trong công việc của nhân viên lên rất nhiều. Điều này được lý giải rằng, việc một cá nhân sử dụng mạng xã hội cho các mục đích khác trong thời gian làm việc sẽ làm giảm sự tập trung trong công việc, và vô tình kéo theo sự căng thẳng trong công việc. 


\subsection{2. Ủng hộ giả thuyết $H 2$}

Kết quả này là trái ngược so với nghiên cứu của Cao và Yu (2019): việc sử dụng quá mức nhu cầu thụ hưởng của phương tiện truyền thông xã hội tại nơi làm việc không ảnh hưởng đến sự căng thẳng trong công việc của nhân viên. Cũng tương tự như việc sử dụng quá mức nhu cầu xã hội, có nhiều nguyên nhân tạo ra sự khác biệt, theo Nicholson và cộng sự (2005), việc một nhân viên bị phân tâm vào các hoạt động khác sẽ dẫn đến sự căng thẳng trong công việc. Thực tế tại Ủy ban nhân dân quận Bình Thạnh, theo buổi thảo luận nghiên cứu định tính lần hai, việc một nhân viên trong giờ làm việc nếu tận hưởng thời gian nghỉ ngơi, thư giãn, cũng như tận hưởng thú vui cá nhân quá mức sẽ dẫn đến căng thẳng trong công việc.

\subsubsection{Giả thuyết H3 không được ủng hộ}

Khi dành một lượng thời gian lớn để tạo và thu thập thông tin trong giờ làm việc, nhân viên tiếp xúc với quá nhiều thông tin so với mức cần thiết (Landers \& Schmidt, 2016), tuy nhiên các đáp viên trong nghiên cứu này lại cho rằng, việc một sử dụng thời gian để tìm kiếm kiến thức, chia sẻ và học hỏi lẫn nhau sẽ không tạo ra sự căng thẳng đáng kể trong công việc của họ. Điều này có thể được giải thích là do tính cách cá nhân của những đáp viên. Một chuyên gia trong nghiên cứu định tính lần hai cho rằng, những nhân viên tại Ủy ban nhân dân quận Bình Thạnh là những người năng nổ, ham học hỏi và nhất là những kiến thức liên quan đến công việc. Vì vậy, họ tiếp xúc với những thông tin có ích với công việc, và không bị căng thẳng khi làm việc. Kết quả này cũng trái ngược với nghiên cứu của Cao và Yu (2019).

\subsection{4. Ủng hộ giả thuyết $H 4$}

Kết quả này tương đồng với các nghiên cứu Hassan và cộng sự (2015); Cao và Yu (2019). Thực tế tại Ưy ban nhân dân quận Bình Thạnh, nhiều nhân viên làm việc không hiệu quả, họ cũng thừa nhận rằng chính họ không thể hoàn thành nhiệm vụ được giao, không dám bảo đảm tính khách quan, hiệu quả của công việc vì họ thường bị cuốn vào những video, hình ảnh hấp dẫn trên mạng xã hội. Thậm chí, về đến nhà họ cũng không thể rời bỏ điện thoại, và cho rằng mình cần lên mạng xã hội để thư giãn. Tuy nhiên, theo quan sát của một chuyên gia khác trong nghiên cứu định tính lần hai, vẫn có một số ít nhân viên có thể kiểm soát được bản thân khi sử dụng mạng xã hội để tìm hiểu và trao đổi công việc với các cá nhân khác.

\subsection{5. Ủng hộ giả thuyết H5}

Kết quả này tương đồng với nghiên cứu của Cao và Yu (2019). Thực tế tại Ủy ban nhân dân quận Bình Thạnh, với tính chất công việc tiếp dân một cửa, hàng ngày có hơn trăm lượt người dân ra vào, nhân viên tiếp xúc và sắp xếp hồ sơ của người dân, có khách nộp hồ sơ, có khách thì lấy hồ sơ, nếu không cẩn thận, nhiều hồ sơ sẽ bị lẫn vào nhau, thậm chí là mất hồ sơ. Người dân đợi chờ lâu thì xảy ra tình trạng khiếu nại thông qua máy đánh giá sự hài lòng để trên bàn làm việc của từng nhân viên. Chỉ riêng tính chất công việc tiếp dân đủ khiến nhiều nhân viên bị căng thẳng. Ngoài ra, người lao động còn phải thực hiện nhiều công việc khác như xây dựng kế hoạch dài hạn và hàng năm; chương trình, biện pháp tổ chức thực hiện nhiệm vụ cải cách hành chính nhà nước trong các lĩnh vực. Mỗi ngày phải thực hiện các văn bản pháp luật, các quy hoạch, kế hoạch, chương trình đã được cấp có thẩm quyền phê duyệt; thông tin, tuyên truyền, phổ biến, giáo dục pháp luật và tham mưu, giúp Ủy ban nhân dân quận Bình Thạnh theo dõi thi hành pháp luật trong các lĩnh vực trên địa bàn quận; hướng dẫn các cơ quan đơn vị trực thuộc Ủy ban nhân dân quận Bình Thạnh thực hiện các công tác theo sự hướng dẫn của cơ quan cấp trên, các Sở ban ngành thuộc Thành phố. Rõ ràng đây là những công việc phải thực hiện hàng ngày thay vì báo cáo hàng tuần như những doanh nghiệp tư nhân khác. Nếu như không đủ thời gian làm việc mà nhân viên còn dùng phương tiện truyền thông xã hội để thư giãn, hoặc dùng vào việc riêng thì chắc chắn một điều là hiệu quả công việc sẽ không đạt. Cả hai chuyên gia trong nghiên cứu định 
tính lần hai đều đồng ý với nhận định này vì thời gian vừa qua họ đã nhận được rất nhiều báo cáo, phàn nàn từ phòng tiếp dân của Ủy ban nhân dân quận Bình Thạnh về thái độ phục vụ của nhân viên, các loại phí phải đóng không được rõ ràng, thời gian xử lý hồ sơ và trả kết quả.

\section{Kết luận và hàm ý quản trị}

\subsection{Kết luận}

Mục tiêu của nghiên cứu này là xác định các yếu tố và mức độ tác động của phương tiện truyền thông xã hội đến hiệu suất công việc của người lao động tại Ủy ban nhân dân quận Bình Thạnh (Thành phố Hồ Chí Minh) tùy thuộc vào cách sử dụng công nghệ của mỗi người. Ban đầu mô hình nghiên cứu chính thức gồm bốn nhân tố tác động đến sự căng thẳng và ảnh hưởng đến hiệu suất làm việc của người lao động. Kết quả của nghiên cứu đã chỉ ra có ba nhân tố làm ảnh hưởng đến sự căng thẳng tại Ủy ban nhân dân quận Bình Thạnh bao gồm: Sử dụng quá mức nhu cầu xã hội của phương tiện truyền thông xã hội tại nơi làm việc tác động mạnh nhất và đáng kể với sự căng thẳng với mức $\beta=0.215$, Sử dụng quá mức nhu cầu thụ hưởng tác động mạnh thứ hai và đáng kể với sự căng thẳng với mức $\beta=0.190$, và Xung đột công nghệ - công việc tại nơi làm việc tác động thứ ba và đáng kể với sự với căng thẳng với mức $\beta=0.164$. Cuối cùng, sự căng thẳng tại nơi làm việc có mối quan hệ ngược chiều với hiệu suất công việc $\beta=-0.306$ và nhân tố Sử dụng quá mức nhu cầu nhận thức của phương tiện truyền thông xã hội tại nơi làm việc là không được ủng hộ với mức $\beta=0.083$.

\subsection{Hàm ý quản trị}

Mặc dù việc sử dụng hợp lý phương tiện truyền thông xã hội có thể cải thiện mối quan hệ và hiệu suất của người lao động, nhưng hành vi sử dụng quá mức của họ vượt quá mức cho phép có thể gây ra kết quả tiêu cực. Nghiên cứu này nhấn mạnh mặt tối của việc sử dụng phương tiện truyền thông xã hội tại nơi làm việc để có được quan điểm cân bằng về nghiên cứu truyền thông xã hội, đóng góp một phần vào cơ sở lý luận có liên quan. Kết quả nghiên cứu đã chỉ ra rằng việc sử dụng phương tiện truyền thông xã hội tại nơi làm việc quá mức gây ra sự căng thẳng, từ đó dẫn đến hiệu suất làm việc kém. Dựa vào kết quả nghiên cứu và giá trị trung bình của các biến quan sát trong thang đo, nghiên cứu đề xuất các hàm ý quản trị cho Ủy ban nhân dân quận Bình Thạnh (Thành phố Hồ Chí Minh) và các đơn vị khác như sau:

Đầu tiên, quản lý cấp cao nên phát triển các chính sách, quy trình, quy tắc và quy định về việc sử dụng phương tiện truyền thông xã hội và khuyến khích họ sử dụng nó cho mục đích công việc tại nơi làm việc để đạt được lợi ích tối đa thay vì sử dụng cho nhu cầu cá nhân. EUS2 là đạt giá trị trung bình cao nhất (3.866), chứng tỏ đa số người được khảo sát đều sử dụng phương tiện xã hội vào việc làm quen với những người ngoài tổ chức, nhưng cũng chưa chắc rằng những người này có liên quan đến công việc đang làm. Có một phần người được khảo sát họ sử dụng phương tiện xã hội để làm quen với những người mang lại lợi ích cho công việc (EUS4 = 3.796). Điều này trùng khớp với kết quả nghiên cứu định tính lần một, có $5 / 12$ người cho rằng họ có thể dừng lại và tập trung vào công việc ngay sau khi thư giãn.

Thứ hai, nhà quản lý cần tập trung để tìm hiểu cách tích hợp các công nghệ quản lý từ xa với hệ thống làm việc trên máy tính cá nhân của từng nhân viên, từng đội nhóm để vừa quản lý vừa hỗ trợ khả năng làm việc của nhân viên. Song song đó, các nhà quản lý cần theo dõi và đánh giá hiệu quả công việc thường xuyên của người lao động nhằm phát hiện kịp thời những trường hợp sử dụng phương tiện truyền thông quá mức, vượt qua mục đích của công việc. Người lao động đã lạm dụng quá vào việc sử dụng phương tiện truyền thông xã hội để tận hưởng những thú vui cá nhân (EHU4 = 3.976); tận hưởng thời gian nghỉ ngơi $(\mathrm{EHU1}=3.884)$; thư giãn $(\mathrm{EHU} 3=$ 3.848). Chỉ có một số ít là dùng để giải tỏa căng thẳng từ công việc (EHU2 = 3.829). Tuy nhiên, nhìn chung đa số người lao động đã sử dụng phương tiện truyền thông một cách quá đà như vậy 
thì điều trước tiên sẽ gây ra tình trạng loãng việc, mờ mắt và căng thẳng.

Thứ ba, nhà quản lý cần trao đổi, chấn chỉnh những nhân viên nào dành nhiều thời gian sử dụng phương tiện truyền thông xã hội, làm cho họ hiểu và nhận thức được hậu quả tiêu cực của nó. Đa số người được hỏi đều cho rằng mình không thể rời bỏ phương tiện truyền thông xã hội $(\mathrm{TWC2}=3.835)$, chính vì điều này đã làm ảnh hưởng khá nhiều đến hiệu suất công việc, khiến người dân không hài lòng về cách xử lý những khiếu nại chậm chạp của nhân viên, thậm chí người lao động còn căng thẳng quát nạt. Họ cần phải nhận ra rằng họ có thể chủ động quản lý hành vi của mình để tránh kết quả tiêu cực tiềm ẩn. Ví dụ, bản thân nhân viên có thể giảm bớt những người bạn không cần thiết trong mạng xã hội của họ và kiểm soát thời gian và tần suất sử dụng của họ. Tại nơi làm việc, khi nhân viên thực hiện nhiệm vụ công việc, nếu không cần thiết, họ có thể đăng xuất khỏi các ứng dụng truyền thông xã hội. Thư giãn thì phải đúng khung giờ nghỉ ngơi. Hơn nữa, nếu người lao động làm việc ở vị trí cần giao tiếp mà buộc phải sử dụng phương tiện truyền thông xã hội rộng rãi để hoàn thành các nhiệm vụ công việc, họ có thể chọn các phương pháp khác nhau để thay thế cho sự phụ thuộc quá mức của họ vào một phương tiện truyền thông xã hội cụ thể. Chẳng hạn, khi nhân viên cảm thấy quá tải về việc liên lạc và tương tác thường xuyên thông qua văn bản trên tin nhắn tức thời, họ có thể chọn cuộc gọi video, gọi thoại, liên lạc qua điện thoại và thậm chí là giao tiếp trực tiếp. Tổ chức nên lưu ý rằng việc sử dụng như vậy của người lao động trong giờ làm việc cũng dẫn đến hậu quả bất lợi.

Thứ tư, theo Kwahk và Park (2016) nghiên cứu tại Hàn Quốc chỉ ra rằng việc sử dụng phương tiện truyền thông xã hội giúp các nhân viên chia sẻ kiến thức, trao đổi công việc đã nâng cao hiệu suất công việc. Do đó, trong thời đại công nghệ 4.0, tổ chức không thể đơn giản cấm hẳn việc sử dụng phương tiện xã hội của người lao động trong công việc, nhưng tổ chức có thể phát triển các chính sách để điều chỉnh hành vi sử dụng của họ. Vì vậy đề xuất rằng nhà quản lý nên tạo ra một cấu trúc nơi phương tiện truyền thông xã hội cũng có thể là một phần của quy trình hoạt động và giúp tăng hiệu suất công việc của nhân viên. Cần tìm hiểu cách tích hợp những công nghệ này với các hệ thống hiện có để hỗ trợ năng lực cho nhân viên làm việc liên quan đến vấn đề cần sáng tạo. Cung cấp các hướng dẫn để giáo dục nhân viên về cách thức, thời điểm và phương tiện truyền thông xã hội nào nên được sử dụng và nên tránh. Hoặc là có thể lập đội nhóm làm việc trên phương tiện truyền thông xã hội chẳng hạn như Zalo, Viber, Google Meet ... để có thể họp hoặc trao đổi thông tin mọi lúc mọi nơi ngay cả khi tan giờ làm. Sau đó đặt ra những hạn mức, mục tiêu công việc, đưa ra những hình phạt hoặc những phần thưởng hợp lý cho những cá nhân có đóng góp tích cực trong công việc để các đội nhóm phấn đấu đạt được mục tiêu. Các chính sách này ủng hộ việc sử dụng phương tiện truyền thông xã hội có trách nhiệm của người lao động và giúp giảm thiểu hậu quả tiêu cực cho họ và tổ chức từ đó nâng cao năng suất làm việc và giảm những căng thẳng không đáng có khi người lao động cũng thú nhận rằng làm việc cả ngày với phương tiện truyền thông xã hội khiến họ căng thẳng $(\mathrm{STR} 3=3.922)$.

\section{Tài liệu tham khảo}

Aichner, T., \& Jacob, F. (2014). Measuring the degree of corporate social media use. International Journal of Market Research, 57(2), 257-273.

Ahuja, M., Chudoba, K. M., Kacmar, C., Mcknight, D. H., \& George, J. F. (2007). IT road warriors: Balancing work-family conflict, job autonomy and work overload to mitigate turnover intentions. MIS Quarterly, 31(1), 1-17.

Alalwan, A. A., Rana, N. P., Dwivedi, Y. K., \& Algharabat, R. (2017). Social media in marketing: A review and analysis of the existing literature. Telematics and Informatics, 34(7), 1177-1190. 
Amabile, T. M., Conti, R., Coon, H., Lazenby, J., \& Herron, M. (1996). Assessing the work environment for creativity. Academy of Management Journal, 39(5), 1154-1184.

Aral, S., Dellarocas, C., \& Godes, D. (2013). Introduction to the special issue-social media and business transformation: A framework for research. Information Systems Research, 24(1), 3-13.

Ayyagari, R., Grover, V., \& Purvis, R. L. (2011). Technostress: Technological antecedents and implications. MIS Quarterly, 35(4), 831-858.

Barling, J., Cheung, D., \& Kelloway, E. K. (1996). Time management and achievement striving interact to predict car sales performance. Journal of Applied Psychology, 81(6), 821-840.

Baron, R. S. (1986). Distraction-conflflict theory: Progress and problems. In L. Berkowitz (Ed.), Advances in experimental social psychology (pp. 1-40). New York, NY: Academic Press.

Cao, X., \& Ali, A. (2018). Enhancing team creative performance through social media and transactive memory system. International Journal of Information Management, 39(4), 69-79.

Cao, X., \& Yu, L. (2019). Exploring the influence of excessive social media use at work: A three-dimension usage perspective. International Journal of Information Management, 46(6), 83-92.

Carr, C. T., \& Hayes, R. A. (2015). Social media: Defining, developing, and divining. Journal of Communication, 23(1), 46-65.

Caplan, S., \& High, A. C. (2006). Beyond excessive use: The interaction between cognitive and behavioral symptoms of problematic Internet use. Communication Research Reports, 23(4), 265-271.

Catalsakal, S. (2016). How trait mindfulness is related to job performance and job satisfaction: Self-regulation as a potential mediator (Master's thesis, Middle East Technical University, Çankaya Ankara, Turkey). Retrieved June 10, 2020, from https://open.metu.edu.tr/bitstream/handle/11511/26007/index.pdf

Davis, R. A. (2001). A cognitive-behavioral model of pathological internet use. Computers in Human Behavior, 17(2), 187-195.

Dwivedi, Y. K., Kapoor, K. K., \& Chen, H. (2015). Social media marketing and advertising. The Marketing Review, 15(3), 289-309.

Fornell, C., \& Larcker, D. F. (1981). Structural equation models with unobservable variables and measurement error: Algebra and statistics. Journal of Marketing Research, 11(8), 382-388.

Haque, A. U., \& Aston, J. (2016). A relationship between occupational stress and organizational commitment of i.t sector \& employees in contrasting economies. Polish Journal of Management Studies, 14(1), 95-105.

Hassan, H. A., Nevo, D., \& Wade, M. (2015). Linking dimensions of social media use to job performance: The role of social capital. Journal of Strategic Information Systems, 18(1), 225-239.

Hoang, T., \& Chu, N. N. M. (2008). Phân tích dĩ liệu nghiên cứu với SPSS [Analyze research data with SPSS]. Ho Chi Minh City, Vietnam: NXB Hồng Đức. 
Janssen, O., \& Yperen, N. W. V. (2004). Employees' goal orientations, the quality of leadermember exchange, and the outcomes of job performance and job satisfaction. Academy of Management Journal, 47(3), 368-384.

Jöreskog, K. G. (1971). Statistical analysis of sets of congeneric tests. Psychometrika, 36(2), 109-133.

Kane, G. C., Alavi, M., Labianca, G., \& Borgatti, S. (2012). What's different about social media networks? A framework and research agenda. MIS Quarterly, 3(1), 1-69.

Kanter, R. M. (1988). When a thousand flowers bloom: Structural, collective, and social conditions for innovation in organizations. Research in Organizational Behavior, 10(1), 169-211.

Kaplan, A. M., \& Haenlein, M. (2012). Social media: Back to the roots and back to the future. Journal of Systems and Information Technology, 14(2), 101-104.

Katz, D. (1964). The motivational basis of organizational behavior. Behavioral Science, 9(1), 131-133.

Kwahk, K. Y., \& Park, D. H. (2016). The effects of network sharing on knowledge-sharing activities and job performance in enterprise social media environments. Computers in Human Behavior, 55(2), 826-839.

Koch, H., Gonzalez, E., \& Leidner, D. E. (2012). Bridging the work/social divide: The emotional response to organizational social networking sites. European Journal of Information Systems, 21(6), 699-717.

Landers, R. N., \& Schmidt, G. B. (2016). Social media in employee selection and recruitment: Theory, practice, and current challenges. Cham, AG Switzerland: Springer International Publishing.

Lazarus, R. S., \& Folkman, S. (1987). Stress, appraisal \& coping. New York, NY: Springer Publishing Company.

Lee, Y. C., Wang, Y. C., Lu, S. C., Hsieh, Y. F., Chien, C. H., Tsai, S. B., \& Dong, W. (2016). An empirical research on customer satisfaction study: A consideration of different levels of performance. Springer Plus, 5(1), 15-77.

Macnamara, J., \& Zerfass, A. (2012). Social media communication in organizations: The challenges of balancing openness, strategy, and management. Journal of Strategic Communication, 6(4), 287-308.

Madsen, D. O., \& Slatten, K. (2015). Social media and management fashions. Cogent Business \& Management, 2(1), 2-17.

Maier, C., Laumer, S., Eckhardt, A., \& Weitzel, T. (2015). Giving too much social support: Social overload on social networking sites. European Journal of Information Systems, 24(5), 447-464.

Moskaliuk, J., \& Kimmerle, J. (2009). Using wikis for organizational learning: Functional and psycho-social principles. Development and Learning in Organizations: An International Journal, 23(4), 21-24.

Moqbel, M., Nevo, S., \& Kock, N. (2013). Organizational members' use of social networking sites and job performance: An exploratory study. Information Technology \& People, 26(3), 240-264. 
Nguyen, T. D.(2013). Phwơng pháp nghiên cúu khoa học trong kinh doanh [Scientific research methods in business]. Ho Chi Minh City, Vietnam: Nhà xuất bản Lao Động - Xã Hội.

Nicholson, D. B., Parboteeah, V. D., Nicholson, J. A., \& Valacich, J. S., (2005). Using distraction-conflict theory to measure the effects of distractions on individual task performance in a wireless mobile environment. Proceedings of the 38th annual hawaii international conference on system sciences, 1-9. doi:0.1109/HICSS.2005.657

Niemz, K., Griffiths, M., \& Banyard, P. (2005). Prevalence of pathological internet use among university students and correlations with self-esteem, the general health questionnaire, and disinhibition. Cyber Psychology \& Behavior, 8(6), 562-570.

Ofir, T., Alexander, S., \& Bontis, N. (2011). Family and work-related consequences of addiction to organizational pervasive technologies. Information \& Management, 48(2/3), 88-95.

O'Reilly, C. A., \& Chatman, J. (1986). Commitment and psychological attachment: The effects of compliance, identification, and internalization on prosocial behavior. Journal of Applied Psychology, 71(3), 492-499.

Ou, C. X. J., \& Davison, R. M. (2011). Interactive or interruptive? Instant messaging at work. Decision Support Systems, 52(1), 61-72.

Özdemir, S., \& Erdem, R. (2016). The role of social media in organizational communication MANAS. Journal of Social Studies, 5(4), 247-269.

Park, N., Kee, K. F., \& Valenzuela, S. (2009). Being immersed in social networking environment: Facebook groups, uses and gratifications, and social outcomes. Cyber Psychology, Behavior, and Social Networking, 12(6), 729-733.

Schmidt, G. B., Lelchook, A. M., \& Martin, J. E. (2016). The relationship between social media co-worker connections and work-related attitudes. Computers in Human Behavior, 55(A), 439-445.

Scott, S. G., \& Bruce, R. A. (1994). Determinants of innovative behavior: A path model of individual innovation in the workplace. Academy of Management Journal, 37(3), 580-607.

Sheer, V. C., \& Rice, R. E. (2017). Mobile instant messaging use and social capital: Direct and indirect associations with employee outcomes. Information \& Management, 54(1), 90-102.

Song, Q., Wang, Y., Benitez, J., Chen, Y., \& Hu, J. (2019). Impact of the usage of social media in the workplace on team and employee performance. Information \& Management, 56(8), 103-160.

Srivastava, S., Pant, M., Abraham, A., \& Agrawal, N. (2015). The technological growth in ehealth services. Computational and Mathematical Methods in Medicine, 2015(4), 1-18.

Sun, Y., \& Shang, R. A. (2014). The interplay between users' intraorganizational social media use and social capital. Computers in Human Behavior, 37(8), 334-341.

Sparrowe, R. T., Liden, R. C., Wayne, S. J., \& Kraimer, M. L. (2001). Social networks and the performance of individuals and groups. Academy of Management Journal, 44(2), 316-325.

Tajvidi, R., \& Karami, A. (2017). The effect of social media on firm performance. Computers in Human Behavior, 3(1), 1-10.

Wang, C., Lee, M. K., \& Hua, Z. (2015). A theory of social media dependence: Evidence from microblog users. Decision Support Systems, 69(1), 40-49. 
Wisniewski, P. K., \& Lu, Y. (2010). When more is too much: Operationalizing technology overload and exploring its impact on knowledge worker productivity. Computers in Human Behavior, 26(5), 1061-1072.

Yang, H. L., \& Lin, R. X. (2017). Determinants of the intention to continue use of SoLoMo services: Consumption values and the moderating effects of overloads. Computers in Human Behavior, 73(8), 583-595.

Zahoor, S., \& Qureshi, I. (2017). Social media marketing and brand equity: A literature review. IUP Journal of Marketing Management, 16(1), 47-64.

Zhang, X. Y., Gao, Y., Chen, H., Sun, Y., \& Pablos, P. O. D. (2015). Enhancing creativity or wasting time? The mediating role of adaptability on social media-job performance relationship. Pacific Asia Conference on Information Systems, 8(2015), 85-99.

Zoonen, W. V., Verhoeven, J. W., \& Vliegenthart, R. (2017). Understanding the consequences of public social media use for work. European Management Journal, 35(5), 595-605. 